\title{
(息)
}

Citation:

Van Horssen, JJ (2018) Locality and Contamination Along the Transnational Asbestos Commodity Chain. In: Histories of Technology, the Environment, and Modern Britain. University College London Press, London, pp. 62-75. ISBN 9781911576570

Link to Leeds Beckett Repository record:

https://eprints.leedsbeckett.ac.uk/id/eprint/7219/

Document Version:

Book Section (Published Version)

Creative Commons: Attribution 4.0

The aim of the Leeds Beckett Repository is to provide open access to our research, as required by funder policies and permitted by publishers and copyright law.

The Leeds Beckett repository holds a wide range of publications, each of which has been checked for copyright and the relevant embargo period has been applied by the Research Services team.

We operate on a standard take-down policy. If you are the author or publisher of an output and you would like it removed from the repository, please contact us and we will investigate on a case-by-case basis.

Each thesis in the repository has been cleared where necessary by the author for third party copyright. If you would like a thesis to be removed from the repository or believe there is an issue with copyright, please contact us on openaccess@leedsbeckett.ac.uk and we will investigate on a case-by-case basis. 


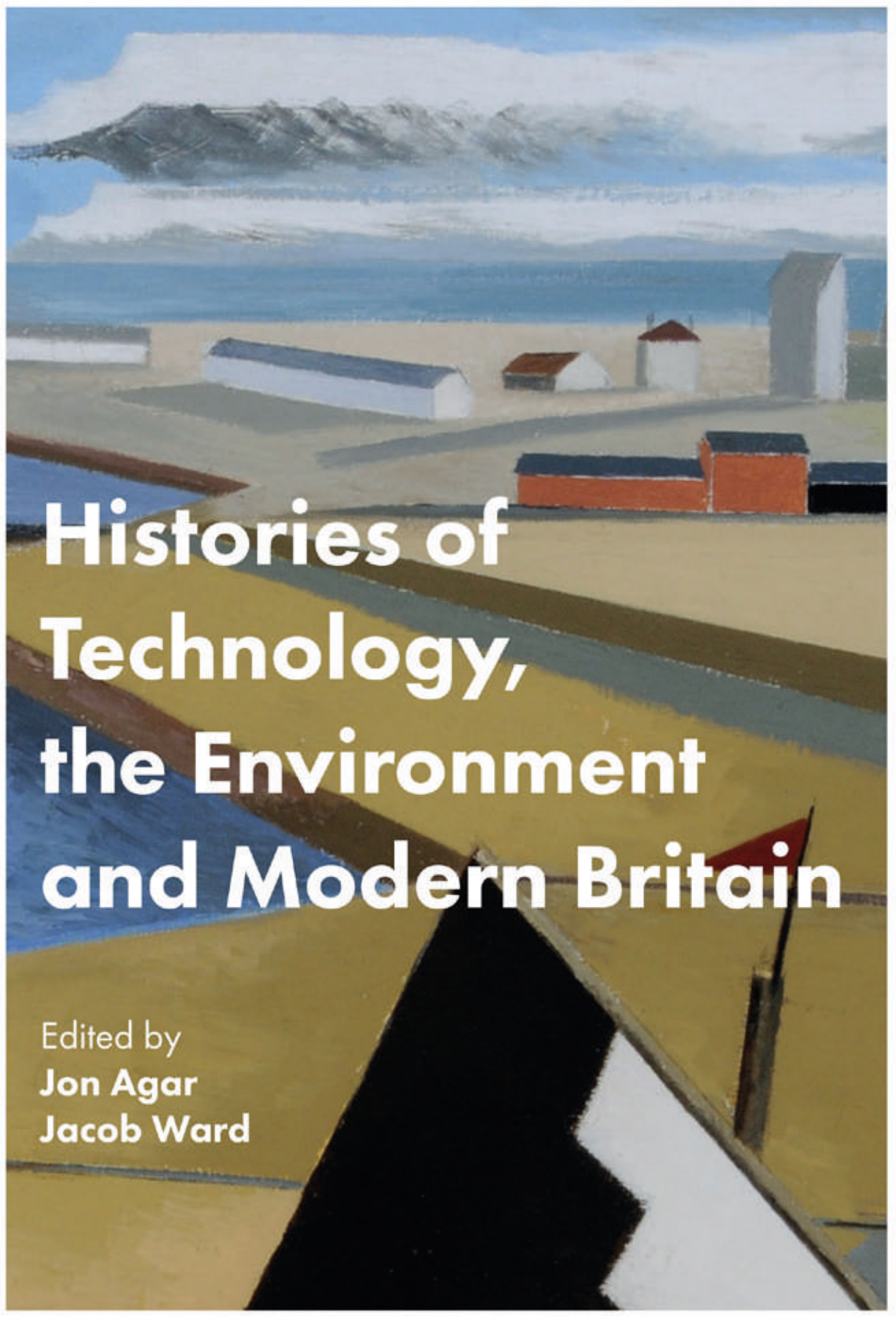

${ }^{\wedge}$ UCLPRESS 
Histories of Technology, the Environment and Modern Britain 


\section{Histories of \\ Technology, the \\ Environment and \\ Modern Britain}

Edited by Jon Agar and Jacob Ward

${ }^{\star}$ UCLPRESS 
First published in 2018 by

UCL Press

University College London

Gower Street

London WC1E 6BT

Available to download free: www.ucl.ac.uk/ucl-press

Text (C) Contributors, 2018

Images (C) Contributors and copyright holders named in the captions, 2018

The authors have asserted their rights under the Copyright, Designs and

Patents Act 1988 to be identified as the authors of this work.

A CIP catalogue record for this book is available from The British Library.

This book is published under a Creative Commons 4.0 International license (CC BY 4.0).This license allows you to share, copy, distribute and transmit the work; to adapt the work and to make commercial use of the work providing attribution is made to the authors (but not in any way that suggests that they endorse you or your use of the work). Attribution should include the following information:

Agar, J. and Ward, J. (eds.). 2018. Histories of Technology, the Environment and Modern Britain. London: UCL Press. DOI: https://doi.org/10.14324/111.9781911576570

Further details about Creative Commons licenses are available at http://creativecommons.org/licenses/

ISBN: 978-1-911576-59-4 (Hbk.)

ISBN: 978-1-911576-58-7 (Pbk.)

ISBN: 978-1-911576-57-0 (PDF)

ISBN: 978-1-911576-60-0 (epub)

ISBN: 978-1-911576-61-7 (mobi)

ISBN: 978-1-911576-62-4 (html)

DOI: https://doi.org/10.14324/111.9781911576570 


\section{Acknowledgements}

The editors would like to express their sincere thanks to all who helped see this collection to publication. In particular, the British Society for the History of Science and the UCL Department of Science and Technology Studies (STS) financially supported the initial workshop, 'Technology, Environment and Modern Britain', held in April 2016. Many thanks to all who participated in the workshop's presentations and discussions. Thank you to Sue Walsh for her help in organizing them. The editors would also like to express their appreciation to UCL Press, especially Chris Penfold, and all involved in the anonymous peer review process. 


\section{Contents}

List of figures ix

Notes on contributors $\quad \mathrm{x}$

1 Technology, environment and modern

Britain: historiography and intersections $\quad 1$

Jon Agar

2 Encroaching Irish bogland frontiers: science, policy and aspirations from the 1770 s to the 1840 s

Esa Ruuskanen

3 Landscape with bulldozer: machines, modernity and environment in post-war Britain

Ralph Harrington

4 Locality and contamination along the transnational asbestos commodity chain

Jessica van Horssen

5 A machine in the garden: the compressed air bath and the nineteenth-century health resort

Jennifer Wallis

6 The Agriculture Gallery: displaying modern farming in the Science Museum

David Matless

7 About Britain: driving the landscape of Britain (at speed?) Tim Cole

8 Crops in a machine: industrialising barley breeding in twentieth-century Britain

Matthew Holmes

9 Plants are technologies

Dominic J. Berry 
10 Oceanscapes and spacescapes in North Atlantic communications

Jacob Ward

11 The Thames Barrier: climate change, shipping and the transition to a new envirotechnical regime Matthew Kelly

12 The woods for the state Mat Paskins

13 The UK government's environmentalism: Britain, NATO and the origins of environmental diplomacy Simone Turchetti

14 Simulating the global environment: the British Government's response to The Limits to Growth Thomas Turnbull

Bibliography $\quad 300$

Index 


\section{Figures}

3.1 A picture taken in the spring of 1944 of the US Army engineer depot at Thatcham, Berkshire, showing massed ranks of bulldozers and tractors being prepared to accompany the D-Day invasion forces

3.2 The construction of the M1 motorway through

Bedfordshire in 1959 is marked by a swathe of bare earth, cleared and levelled by an army of machines such as the bulldozer prominent in the foreground

3.3 Front cover of The Ecologist, July 1972

5.1 The Hydropathic Establishment at Ben Rhydding 79

5.2 J.A. Fontaine's Parisian Établissement Médico-Pneumatique

5.3 The interior of Malvern's compressed air bath as depicted in Ralph Barnes Grindrod's Malvern: Its Claims as a Health Resort (1871)

5.4 The building that housed Ben Rhydding's compressed air bath, from R. Wodrow Thomson's Ben Rhydding: The Asclepion of England (1862)

5.5 The exterior of Malvern's compressed air bath, from Ralph Barnes Grindrod's Malvern: Its Claims as a Health Resort (1871)

6.1 Detail of 'Threshing' diorama 106

6.2 Detail of 'Manuring and Potato Planting, 1850' diorama 112

6.3 'Tractor Ploughing, 1917' diorama 114

6.4 Detail of 'Summer' diorama 116

6.5 Detail of crop spraying diorama showing the 'Allman High/Low Volume Sprayer'

9.1 Ormskirk show organisers, 1920. Group photograph of the Ormskirk show organisers for the year 1920, published in the Preston Guardian, 30 October 1920

9.2 Example of a potato experiment photograph from Salaman's 1910 notebook 


\section{Contributors}

Jon Agar is Professor of Science and Technology Studies at the Department of Science and Technology Studies (STS), UCL. He is the author of Science in the Twentieth Century and Beyond (2012), Constant Touch: a Global History of the Mobile Phone (2003, second edition 2013), and The Government Machine (2003). He was awarded the Wilkins-BernalMedawar Prize and Lecture by the Royal Society in 2016.

Dominic J. Berry is a Research Fellow on the Engineering Life project (ERC grant number 616510-ENLIFE). His research integrates the history, philosophy, and sociology of biology and biotechnology from 1900 to the present, concentrating on heredity, agriculture and biological engineering.

Tim Cole is Professor of Social History at the University of Bristol and currently Director of the Brigstow Institute. His research interests are primarily in historical landscapes, with a particular focus on geographies of the Holocaust. He is the author of Images of the Holocaust/ Selling the Holocaust (1999), Holocaust City (2003), Traces of the Holocaust (2011) and Holocaust Landscapes (2016), and co-editor of Militarised Landscapes (2010) and Geographies of the Holocaust (2014). He is currently writing an environmental history of post-war Britain.

Ralph Harrington studies at the School of Fine Art, History of Art and Cultural Studies at the University of Leeds.

Matthew Holmes is completing his PhD thesis at the University of Leeds exploring the history of plant biotechnology and its application to British agriculture since the 1950s, from the manipulation of crop plants through hybridisation and irradiation to the rise of genetic biotechnology. His other research interests include species history and the history of nineteenth-century natural history.

Matthew Kelly is Professor of Modern History in the Department of Humanities, Northumbria University. He works on modern British 
history, focusing on the development of environmental policy in the post-war period, the cultural history of landscape, and the history of National Parks and nature conservation. Matthew joined Northumbria University in 2016 as a professor. Previously he was Associate Professor at Southampton, following a British Academy Postdoctoral Research Fellowship at the University of Oxford. In 2012-13, he was a Fellow of the Rachel Carson Center, Ludwig Maximilian University, Munich and in 2016 Visiting Researcher at St John's College, Oxford.

David Matless is Professor of Cultural Geography at the University of Nottingham. He is the author of Landscape and Englishness (1998, revised edition 2016), and editor of The Place of Music (1998) and Geographies of British Modernity (2003). His 2014 book, In the Nature of Landscape: Cultural Geography on the Norfolk Broads, is a study in regional cultural landscape. A related 2015 volume, The Regional Book, develops work on geographical description through an account of the Broads region. His wider areas of publication include the life and work of ecologist/artist Marietta Pallis (with Laura Cameron), British geographical studies of the Eastern bloc (with Adam Swain and Jonathan Oldfield), geographies of sound, the landscapes of documentary film and the geography of ghosts. Current research addresses landscape and English identity since the 1960s, and the cultural geographies of the Anthropocene via the theme of the coastal 'Anthroposcenic'.

Mat Paskins is Postdoctoral Research Assistant on the AHRC-funded Unsettling Scientific Stories project, Aberystwyth University.

Esa Ruuskanen is an Academy Research Fellow in the Department of History, Cultures and Communication Studies at the University of Oulu, Finland. His research interests are environmental history and the environmental humanities with a focus on environmental values and environment-technology interaction. In recent years, he has focused on human-peatland relationships and the emergence of conservation ideas in the Nordic countries and Ireland from the eighteenth century onwards.

Simone Turchetti is a Lecturer at the Centre for History of Science, Technology and Medicine at the University of Manchester. His research interests span the history of twentieth-century science and technology, the history of the geosciences, the historiography of science, and science and international relations. He was Principal Investigator on the ERC-funded project The Earth Under Surveillance (TEUS). 
Thomas Turnbull is a Visiting Postdoctoral Fellow at the Max Planck Institute for the History of Science (MPIWG) Department 1, having completed a PhD at the University of Oxford in 2017. His work for this volume was supported by the ESRC and the Institute for Electrical and Electronics Engineers (IEEE) Fellowship in the History of Electrical and Computing Technology.

Jessica van Horssen is a Senior Lecturer at the School of Cultural Studies \& Humanities, Leeds Beckett University. She is the author of A Town Called Asbestos: Environmental Contamination, Health, and Resilience in a Resource Community (2016).

Jennifer Wallis is a Lecturer in Cultural and Intellectual History at the School of History, Queen Mary University of London. Her primary research interest is the history of psychiatry and medicine in the nineteenth and early twentieth centuries. She is particularly interested in integrating these fields with histories of the body; for example, looking at how patients interacted with medical technologies and the body as a site of scientific investigation and experimentation. She is completing her first monograph, Investigating the Body in the Victorian Asylum, and beginning work on a second, on the history of resuscitation from the nineteenth century to the present. She also works on film history, particularly British film and the horror/ exploitation genres.

Jacob Ward is completing a PhD thesis at UCL on the history of information, control and research at the UK General Post Office and British Telecom, before taking up a position as The Bodleian's Byrne-Bussey Marconi Visiting Fellow, University of Oxford. 


\section{Locality and contamination along the transnational asbestos commodity chain}

Jessica van Horssen

Natural resources often take widespread, diverse paths as they are removed from their natural habitat, shipped to factories either near or far, and processed into marketable goods available around the world. But what happens when a natural resource is toxic? How does contamination change at each stage along its global commodity chain? How have the risks toxic resources pose to human health been regulated by those in positions of power in ways that overlook those most vulnerable in society?

This chapter examines these questions by following transnational contamination along the Canadian asbestos commodity chain, which I call the 'contamination chain'. For the purpose of this chapter, I will focus on the transnational path asbestos took from Canadian mines to factories and homes in Greater Manchester during the interwar and postwar period. Canada extracted the majority of the world's asbestos in the twentieth century, and British politicians, city planners and consumers saw the fireproof mineral as being crucial to creating safe, long-lasting communities. When it came to asbestos, however, it was never as simple as supply and demand, and with this chapter, I intend to broaden our understanding of environmental and social justice through a close examination of how the people of Manchester came to experience toxicity in both the workplace and the home.

Philosopher of science Bruno Latour calls asbestos 'a perfect substance', and 'one of the last objects that can be called modernist' before the illusions of its modernity were revealed by large-scale disease rates and workers' compensation cases. ${ }^{1}$ It is important to remember, as outlined in the opening chapter of this volume, that environmental artefacts like asbestos could only be deemed both a 'perfect substance' 
and a tool of contamination after going through an intense technological process. In this way, asbestos is a technological artefact, reflecting both society's ambition to protect itself from the dangers of fire and society's fear of being harmed by the very thing thought to protect.

Asbestos is a fireproof mineral formed deep within the Earth's crust during the Devonian period between 410 and 355 million years ago, as large land masses broke apart and collided. This occurred throughout the world, but in the case of Canada's 'asbestos belt', the mineral developed along with the Appalachian Mountain Range in what is now the Eastern Townships region of the French Canadian province of Quebec. The friction and heat involved in the formation of the Appalachians chemically reconstituted the serpentine rock at this particular site, and in its re-crystallisation, the chemical composition was changed and veins of asbestos fibre formed. ${ }^{2}$ The asbestos located in this region is composed of magnesium, silicon and oxygen $\left(\mathrm{Mg}_{3} \mathrm{Si}_{2} \mathrm{O}_{5}(\mathrm{OH})_{4}\right)$ and is able to withstand temperatures in excess of $3,000^{\circ} \mathrm{F}^{3}$

Although formed millions of years ago, the largescale human use of asbestos only really began in the late nineteenth century when rising population rates and the industrialisation of the Western world enabled the development of the technological systems required to process the mineral into marketable, fireproof goods. Surveyors for the Geological Survey of Canada first noted the presence of asbestos in the Eastern Townships in the 1840s and described it as a nuisance that ruined perfectly marketable slate. ${ }^{4}$ Indeed, it wasn't until the 1870 s that the fireproof qualities of the mineral became more widely known and market demand began to grow. With this came a technological revolution of the landscape, as farms and forests began to be replaced by massive open pit asbestos mines in the Eastern Townships of Quebec.

Examining the path asbestos took from local mine to global market, from Canadian mines to Manchester factories and homes, informs us of the different ways society has interpreted risk, blame and the legacies of environmental contamination and justice. Environmental contamination rarely, if ever, respects artificial borders: wind, water and species transport toxic resources and waste beyond seemingly contained sites, and result in different forms of exposure and contamination. ${ }^{5}$ What's more, these different forms of exposure often result in different diseases, and this chapter examines the impact history of asbestos as a technological artefact impacting health and safety in a multitude of ways within different environments.

Asbestos exposure causes three main diseases: asbestosis, lung cancer and mesothelioma. Asbestosis is the hardening of the fluid lining 
of the lungs due to the inhalation of large amounts of asbestos fibre over a number of years, resulting in death by suffocation, when lungs can no longer expand and contract with each breath. This was particularly common in factory workers in places like Manchester, where large amounts of asbestos dust would be raised in the process of manufacturing marketable goods. Lung cancer and mesothelioma were more difficult for medical researchers to diagnose because they usually occur after fairly limited exposure to asbestos - a carcinogenic mineral - and so the causal factor in these cases was often overlooked, although mesothelioma is only caused by exposure to asbestos.

In this chapter, I analyse the different ways Canadian miners and the people of Manchester, England became exposed to asbestos at different stages along its contamination chain. Left untouched, deep within the Earth's crust, asbestos is a benign substance. It was only when humans decided to extract the mineral and apply it to modern technologies that the issue of contamination arose, but it did so differently along the commodity chain, at place-specific stages of exposure. While there can be end points for extracted natural resources, the method of processing and moving large quantities of the environment through technological systems creates legacies of contamination and disease far beyond a single resource community or end destination. Thus, this chapter examines the significance of how locality works to define resource toxicity along transnational commodity chains of natural resources.

\section{Canada's asbestos culture}

The first site of exposure to Canadian asbestos was in the mining communities of the Eastern Townships of Quebec, where citizens lived (and breathed) the industry on their doorsteps. ${ }^{6}$ The residents of these communities were the French Canadian Catholic 'worker bees' and their families who were disconnected from the information and resources of their American or British counterparts due to language barriers and access issues. Foreign companies like Britain's Turner \& Newall and America's Johns-Manville supplied wages, housing and medical care to these workers, and the Catholic Church supplied the union.

Asbestos was mined in these communities in large, open cast pits that allowed for maximum fibre extraction without the risk of collapsing tunnels underground. Geological engineers at the turn of the twentieth century saw open cast asbestos mining as a real advantage long before anyone was aware of the hazards the mineral posed to human health, as 
it allowed workers access to fresh air throughout the extraction process, which was significantly different from other mining industries like coal. ${ }^{7}$ This was a 'healthy' way to mine.

Indeed, once the dangers of the mineral started to become known in places like Manchester, industry officials and doctors used Canadian miners as evidence to prove that asbestos was not dangerous to human health, and their open air exposure to the mineral was a key factor in this campaign. Because of the open pits in these communities, the level of hazardous dust exposure in the mines themselves was fairly low in comparison with the factory-based exposure in places like Manchester. While there were factories in the Canadian mining communities, they were mostly for light processing of the mineral before shipping it to largerscale operations located along the transnational commodity chain.

This does not mean Canadian asbestos workers were not adversely affected by their exposure to asbestos, but rather that their diseases often differed from those of other workers at other stages in the technological process of making asbestos marketable, resulting in lung cancer and mesothelioma, which occurred around 30 years after first exposure. What's more, the companies that owned these mines kept the workers away from independent medical researchers, and much of their disease realities were obscured by a sophisticated and deliberate corporate effort to hide the hazards of asbestos. ${ }^{8}$ As long as those exposed to the mineral in its purest form remained healthy, the companies invested in the industry could claim the diseases that occurred in Manchester factory workers, for example, were caused by other materials added along the technological process.

Company doctors did not inform these isolated Canadian workers when they contracted asbestos-related disease. The French Canadian workers themselves did not have access to literature on the hazards of the mineral written in their own language. Union leaders were primarily interested in showcasing the mild temperament of their members to make the industry appealing to foreign investors, especially in comparison to the more radical socialist movements sweeping Britain and the United States in the first decades of the twentieth century. This culminated in an intense local pride in Canadian asbestos communities, rooted in the mistaken belief that their work was helping make the world safe, and their product was not what was causing workers at other sites along the commodity chain harm. Once we follow shipments of raw asbestos out of the Canadian mines and mining communities, however, it becomes clear how site-specific exposure during the technological process of making the mineral marketable changes understandings of risk and toxicity. 


\section{Manchester's asbestos culture}

While Manchester may be more widely known historically as 'Cottonopolis' and a birthplace of the Industrial Revolution, ${ }^{9}$ it is this city's history with the cotton industry that made it an ideal place for an asbestos processing industry to develop. ${ }^{10}$ Because it is a fibrous mineral, asbestos is broken apart during the technological process it requires to become a marketable good. In many cases, the mineral's fibres are initially carded and woven much in the same way as cotton, and the two were often blended to create asbestos cloth for a variety of goods, including firefighting and military uniforms, as well as aprons, ironing board covers and oven mitts.

While the fireproof qualities of asbestos had been known for centuries, with Charlemagne even having an asbestos table cloth for party tricks, ${ }^{11}$ it is a natural resource particularly suited to modern, industrialised societies. The intense industrialisation process undertaken during the World Wars, combined with the fact that Britain owned several of the Canadian asbestos mines, meant that it was one of the only European countries importing this valuable material, which the American Minerals Yearbook termed 'indispensable to modern life' in 1939. ${ }^{12}$

Over the span of the first half of the twentieth century, asbestos became part of the culture in Manchester. Not only was the cotton industry particularly suited for an asbestos transition, but so too were the people. Manchester shared this 'asbestos culture' with those in the mining communities of Canada, although it had important, site-specific differences as well, rooted in the different forms of exposure that occurred on the factory floor, compared with the open mine.

The context in which British factory workers experienced and accessed information on industrial disease also differed from that of their Canadian counterparts. Britain had a much longer history of a strong labour movement, workers generally went to doctors who weren't paid by the companies they worked for, and the asbestos workers in Manchester spun, wove and processed the mineral in a way that created much more dust in a confined space compared with the Canadian miners who worked in an open pit. ${ }^{13}$ These British factories were a new 'site of contamination' for Canadian asbestos and they fostered a disease awareness that was simply non-existent in Canada at this time.

Although Britain had no domestic asbestos mines, it is where the first recorded death from asbestos-related disease in the world occurred in $1907 .{ }^{14}$ This death of a British textile worker was subject to an inquest, which discovered the victim's lungs had hardened due to the inhalation 
of asbestos fibres, but no action against the resource or the industry followed, and market demand for the mineral continued to grow. The fact that the first recorded asbestos-related death occurred in Britain, rather than in any of the mining communities that interacted with the mineral in its rawest form, is indicative of the impact of technological processing on the resource, bringing it into contact with humans in a way that had never been experienced before.

After the textile worker's death in 1907, the British medical community was tuned into the asbestos situation. When asbestos textile factory worker Nellie Kershaw died in 1924, her cause of death was quickly determined as being asbestos, and her family was the first to successfully sue an asbestos company for wrongful death. ${ }^{15}$ Kershaw had worked as a spinner for British asbestos magnates Turner \& Newall in Rochdale, Greater Manchester. Turner \& Newall owned and operated mines in both Canada and what is now Zimbabwe, and used a mixture of asbestos fibres in their operations. ${ }^{16}$

Kershaw had worked for Turner \& Newall from 1903, when she was 12 , until 1922, when she was unable to work due to her increasingly severe disease, and obtained a National Health Insurance certificate of ill health due to 'asbestos poisoning'. She would have been exposed to large amounts of raw asbestos at work, and would have taken it home in her hair and on her clothing at the end of each shift. ${ }^{17}$ Despite this obvious connection, Turner \& Newall refused to assist the Kershaw family when she became unable to work.

Dr W.E. Cooke investigated Kerhsaw's death for the British Medical Journal in 1924 and discovered that her lungs were hardened beyond the ability to function due to being packed full of asbestos fibre. Two years later, American asbestos giant, the Johns-Manville Co., faced its first claim for compensation from textile workers in New Jersey, although there remained no claims from Canadian miners, again supporting the corporate lie that Canadian asbestos was benign. ${ }^{18}$ Cooke coined the term 'asbestosis' in 1927 to describe the fatal disease that Kershaw and others had developed. ${ }^{19}$ This was the first asbestos-related disease to be named, and textile factory workers were particularly vulnerable to it due to the high amount of fibre they were exposed to in an enclosed space.

Asbestosis resembled another industrial lung disease rooted in a natural resource that British factory workers were quite familiar with: byssinosis. Especially common in the textile factories located in and around Manchester, byssinosis occurs when lungs fill up with microscopic cotton fibre, resulting in a hardening of the lining and suffocation. ${ }^{20}$ Thus it appeared that while a different natural fibre caused 
asbestosis, its symptoms and progression were similar to other industrial diseases British textile workers were all too familiar with. The British state had shown little inclination to prevent byssinosis, and the same was true for asbestosis. As long as the disease remained within the factory walls, it was not of prime concern to legislators, especially when regulating dust exposure in workers would likely result in slower production rates and lower profits.

By comparison, at this point Canadian asbestos miners had very little information about the state of their bodies, nor did they have any legal recourse if and when they did get ill: asbestos-related disease was not eligible for workers' compensation claims in Canada, and most Canadian asbestos workers were not even unionised by the time of Kershaw's death. ${ }^{21}$ While asbestosis grew to be particularly common in British factories, only a fraction of Canadian asbestos miners were diagnosed with the disease, largely because their exposure to the mineral occurred in a completely different site of contamination, with open pit mining being the majority worker activity, rather than indoor processing. ${ }^{22}$

\section{Industrial vs domestic exposure}

While Cooke's identification of asbestosis made both local and national news in Britain, ${ }^{23}$ it seemed to be simply yet another industrial disease that the working class was vulnerable to, not the general public, so there was no immediate risk prevention regulation to address this problem. Dust was simply a fact of life for many factory workers in Britain at the time,$^{24}$ and it was not seen as something that could - or should - be changed. Throughout this period, reporting on dust exposure and disease was common practice for the British press, especially the local newspapers in the north-west of England. Knowledge about this risk to workers' health was very public, yet action to prevent it was very slow. A public acknowledgement and discussion of asbestosis was almost nonexistent in Canada at this time, with the first newspaper article on asbestosis only appearing in $1949 .{ }^{25}$ There were research articles in Canadian medical journals prior to this, but these were inaccessible to French Canadian asbestos miners, and they were largely edited by the British and American companies that operated the mines. ${ }^{26}$

Despite a general awareness of the dangers asbestos posed to human health in Britain, the problem appeared to be in the dust that was raised while processing asbestos, not in the actual material that was becoming increasingly embedded in so many homes and businesses. This 
was a problem with the technological system the natural resource was processed through on its way to becoming home insulation, an additive to paint, shingles and cement or even brake pad linings for the growing automobile-reliant population. In fact, it wasn't until asbestos-related disease began appearing outside the factory walls that public awareness morphed into public fear.

Indeed, early twentieth-century newspaper advertisements from Manchester indicate how all-pervasive the mineral was in the everyday life of the region's residents. A large advertisement published in the Manchester Guardian in 1919 claimed that asbestos was 'the most perfect scientific building material ... fire-resisting, economical, weatherproof and durable', and would allow homes to be built faster and better than wooden houses. ${ }^{27}$ Another ad, published one year later, boasted about how 'ideal' asbestos cement was for bungalows and schools in the Manchester region. ${ }^{28}$ Because of the manufacturing tradition of northwest England, the factories of the region were particularly adaptable to all types of asbestos processing, whether it be for fabric or building materials. Furthermore, companies like Turner \& Newall, as well as Bell's Asbestos, were active in the Manchester community. Although Turner \& Newall did not assist Nellie Kershaw's family when she became too ill to work due to her occupational exposure to asbestos, in 1923, they proudly donated to the hospitals and infirmaries of Manchester and Salford, helping raise two million shillings and appearing on the Roll of Honour given to the Duke of York on 6 November 1923, less than a year before Kershaw's death. ${ }^{29}$

Homes and hospitals were other 'sites of contamination' along the transnational asbestos commodity chain. Because the asbestos in these sites was usually contained behind walls or underneath flooring, exposure to the mineral was significantly less than occurred in factories. It took much longer for awareness of this contamination to develop because it took longer for the diseases caused by this sort of slow exposure to manifest in the families who lived in these homes, or to catch the attention of the medical professionals who worked in these hospitals. In fact, hospitals often used asbestos in the treatment of other diseases. In 1935, the mineral was used to line baths used by patients suffering from rheumatoid arthritis and was deemed a 'versatile ally of medicine', along with technologies such as the X-ray. ${ }^{30}$ Despite rising disease rates in factory workers, it appeared as though Britain could not get enough asbestos.

As an industrial hub, Manchester was a main target during the Second World War, which brought the local population an appreciation for fireproof homes, as well as an urgent need for new ones. ${ }^{31}$ Thousands 
of homes were destroyed by German bombing in Manchester, as well as other urban industrial centres like London, Liverpool and Birmingham. Children were evacuated to the countryside, factories were destroyed and entire neighbourhoods were erased. Realising this was a growing crisis, especially as the displaced population continued to increase, the British government passed the Temporary Housing Act in 1944, which saw over 100,000 prefabricated asbestos homes assembled all over Britain, including in Manchester. The Canadian Parliament discussed these prefabricated homes, as many of them were constructed with the mineral mined in Canada's asbestos belt.

After much of Manchester's city centre and industrial zone was destroyed by German bombing campaigns, the town council saw an opportunity. ${ }^{32}$ The people who lived in these parts of Manchester were typically poor working-class families, and there were a lot of them: overpopulation was a serious problem. When their homes were destroyed, Manchester City Council attempted to influence or change the social standing of its displaced residents while rebuilding the town so it had a modern urban centre. At the time, even though there was a general awareness about the health risks of the mineral in the UK, the need for fireproof, durable homes was too great to omit one of the most important natural resources of the modern era.

While these prefabricated houses were purchased under the 'temporary homes' programme, many of the small prefabricated asbestos bungalows remained on Britain's urban landscape for decades following the war, and many still remain today. ${ }^{33}$ Asbestos was a fundamental part of these prefabricated homes, as sheet after sheet of asbestos cement were used as walls, floors and ceilings to ensure the families who lived in these structures would be safe from the dangers of fire. ${ }^{34}$ By the end of the Second World War, medical and newspaper reports of asbestosrelated disease still only focused on those who developed it through factory exposure. As far as regulators were concerned, the general public was safe once housed in structures that had indoor plumbing, electricity and state of the art insulation: these homes offered modernity to an urban working class previously stuck in city centre slums.

\section{From the factory to the home: changing sites of exposure and contamination}

Medical knowledge of asbestos-related disease beyond asbestosis and beyond the factory walls took decades to develop, and even longer for 
this knowledge to spread further than confidential industry memos. However, the slow exposure to asbestos that occurred in domestic sites of contamination, as well as in schools, hospitals and government buildings, was eventually the mineral's undoing.

Asbestos causes cancer. Asbestos-related cancers, such as lung cancer and mesothelioma, largely occur in people who are exposed to smaller levels of asbestos fibre. This is the type of exposure that occurs in home renovations, or simply through interacting with asbestos-based products in the home, including aprons and oven gloves. It also widely occurred in Canadian asbestos miners working in an open pit, where dust levels were relatively low.

While the industry used the apparently low rates of asbestosis in Canadian asbestos workers as evidence that the mineral was safe, they also secretly studied the health of these workers because they knew this was untrue. The studies took a variety of forms, but culminated in the secret autopsy of deceased Canadian miners' lungs, which were then transported across the international border to Saranac Laboratory in upstate New York, where they were studied without any public knowledge or repercussion in the 1940s and 1950s. ${ }^{35}$ It was at this lab in 1943 that chief researcher Dr Leroy Gardner 'unintentionally' discovered that asbestos caused cancer. ${ }^{36}$ Saranac researchers discovered 70 cases of unreported asbestos-caused lung cancer in these lungs by $1958 .{ }^{37}$ The families of these deceased miners were never notified, and the risk of cancer to those with low exposure to asbestos was covered up by industry leaders.

As with the case of asbestosis, it was more difficult to hide asbestosrelated disease from workers and the public in Britain because of an engaged labour movement and independent medical researchers who had access to those working with the mineral. The low exposure that led to cancer developing in Canadian miners was also the type of exposure factory workers were vulnerable to once regulation had reduced the amount of fibre dust in the workplace. Manchester's asbestos workers were among the first to be publicly diagnosed with asbestos-related cancer.

In an article published in a 1960 edition of the Lancet, Dr E.E. Keal examined the causes of death of men and women suffering from asbestosis in British processing and manufacturing plants over a prolonged period of time. Keal found that while the majority of male subjects with asbestosis died of carcinoma of the lung, the bulk of the female asbestos-related deaths were caused by carcinoma of the ovary and breast, suggesting that the interaction between asbestos and the female 
body was unique.$^{38}$ While the asbestos industry did not want the dangers asbestos posed to human health to become general knowledge, it especially wanted to avoid any connection between low exposure to asbestos and cancer, which was a disease workers and the general public understood much more than they did asbestosis.

As reports on the connection between asbestos and cancer spread through British society, Liverpool dockworkers refused to unload shipments of asbestos in 1967 unless they were packaged in dust-proof containers, and in March 1968, the British government banned imports of crocidolite asbestos because of the risk it posed to both workers and the general public. ${ }^{39}$ Britain continued to import chrysotile asbestos beyond this point, however, as the health realities of Canadian miners remained hidden, and thus the mineral was still understood to be safe. However, low exposure disease rates remained threatening to the industry because it meant that the domestic and public realm could also be vulnerable to industrial - and environmental - contamination.

Houses in Manchester were a prime location of this contamination. In 1931, Manchester purchased a neighbouring part of Cheshire, on the southern border of the city, in order to address the rising crisis of urban overpopulation. The city had been developing this land since the 1920s, and following the devastation of the Second World War the council fully developed the suburb of Wythenshawe to rehome displaced families. ${ }^{40} \mathrm{In}$ her examinations of the South African asbestos industry, historian Nancy Jacobs explains that, 'it is necessary to recognize that environmental and social justice are linked and that power imbalances will determine the ways men and women, rich and poor, and blacks and whites live with each other and the natural world'. ${ }^{41}$ While asbestos was used in most post-war homes and other buildings because of its remarkable ability to prevent the spread of fire, once the threat of domestic asbestos exposure became public, this was a low-income community that was forgotten by the city when it was arranging asbestos-removal plans, despite the homes largely being owned by the council.

From its beginning, urban planners saw Wythenshawe as the ideal location to house underprivileged families from Manchester's city centre, because it was more or less a blank, green, and leafy canvas. Tree-lined streets, grassy parks and asbestos-filled homes soon came to define Wythenshawe, and it was part of 'the Garden City' movement that began in Britain at the start of the twentieth century, which emphasised the importance of green spaces. ${ }^{42}$

Wythenshawe quickly went from open farmland to one of the largest social housing communities in Europe. Asbestos was fundamental to 
this community project, as well as many others like it. This all sounded ideal, and as though asbestos and Manchester were a perfect match, not only in the region's factories, but also in its homes.

The illusions of Wythenshawe's modernity can be seen as a social experiment designed to elevate the status of the urban poor through Victorian notions of the benefits of green space. In fact, the motivation for this project was similar to the sentiment expressed in early asbestos building material advertisements relating to the speed and perfection it would add when building family homes: governments and businesses looked to the natural environment to shape the behaviours of its population.

In reality, moving poor working-class families out of the urban centre where their jobs were based, and into a distant suburb that didn't have access to reliable public transport, shops or other community infrastructure, eventually became a major problem. Parents were home late from work, the leafy streets and parks offered good cover for criminals, and the asbestos-containing materials and products in these homes posed a serious threat to the health of local underprivileged families, which has yet to be addressed.

\section{Conclusion}

Despite the corporate interest in keeping contamination in factories, asbestos was used in new housing and public buildings in Britain for much of the twentieth century, not just those inhabited by the working class. This was a domestic toxic time bomb just waiting to go off. Once the public realised the threat of non-industrial contamination, however, middle- and upper-class homeowners had the disposable income to get rid of the asbestos in their homes.

Residents of communities like Wythenshawe, however, were less able to make these changes. A pamphlet sent to residents of Wythenshawe by the council's Community Housing Group in the 2000s acknowledged the threat of asbestos in the community's homes, but emphasised that residents should not panic, stating that as long as they did not do any renovations or other activities that could disturb the fibre, they would be fine. ${ }^{43}$ Access to safe homes and reliable knowledge about asbestos contamination remains limited for Manchester's working-class residents, and these limitations have deep historical roots.

Asbestos as a technological and environmental artefact has impacted human health in different ways depending on the locality 
in which people were exposed to the mineral. This varied from open air exposure in Canada's asbestos mines, intense dust exposure in Manchester's factories, and limited, yet still harmful exposure in communities like Wythenshawe. Social class has been a significant factor in the degree to which people were exposed to the mineral, as well as the speed by which government regulators managed - and continue to manage - the risk. Understanding the different ways asbestos was deemed to be toxic in different localities along its transnational commodity chain informs us of the ways in which techno-environmental artefacts are manipulated and managed, and the human repercussions of these processes.

\section{Notes}

1 Bruno Latour, Politics of Nature (Cambridge, MA: Harvard University Press, 2009), 23.

2 Paul D. Ryan, 'Caledonides', in The Oxford Companion to the Earth, ed. Paul Hancock and Brian J. Skinner (Oxford: Oxford University Press, 2000); David A. Rothery, 'Obduction', in The Oxford Companion to the Earth, ed. Paul Hancock and Brian J. Skinner (Oxford: Oxford University Press, 2000); David S. O'Hanley, 'The Origin of the Chrysotile Asbestos Veins in Southwestern Quebec', Canadian Journal of Earth Sciences 24, nos 1-3 (1987): 1-9, 8.

3 Cornelis Klein, 'Rocks, Minerals, and a Dusty World', in Reviews in Mineralogy: Health Effects of Mineral Dusts, ed. Brooke T. Mossman and George D. Guthrie Jr (Chelsea: Mineralogical Society of America, 1993), 17.

4 Alexander Murray, 'Report of Alexander Murray, Esq., Assistant Provincial Geologist, addressed to W.E. Logan, Esq., Provincial Geologist', Canadian Geological Survey (Montreal: Lovell \& Gibson, 1849), 388. 'Asbestus' was an alternative spelling of 'asbestos' at this time.

5 See, for example, Greg Mitman, Michelle Murphy and Christopher Sellers (eds), 'Landscapes of Exposure: Knowledge and Illness in Modern Environments', Osiris 19 (2004).

6 Jessica van Horssen, A Town Called Asbestos: Environmental Health, Contamination, and Resilience in a Resource Community (Vancouver: University of British Columbia Press, 2016).

7 Fritz Cirkel, Asbestos: Its Occurrence, Exploitation and Uses (Ottawa: Mines Branch, Department of the Interior, 1905), 30.

8 For more information on the corporate obstruction of medical evidence, see van Horssen, $A$ Town Called Asbestos.

9 See, for example, Michael Nevell, Cottonopolis: An Archaeology of the Cotton Industry of NorthWest England (Manchester: Manchester University Press, 2017).

10 For background on this transition, see Geoffrey Tweedale, Magic Mineral to Toxic Dust: Turner \& Newall and the Asbestos Hazard (Oxford: Oxford University Press, 2001).

11 Rachel Maines, Asbestos and Fire: Technological Tradeoffs and the Body at Risk (New Brunswick: Rutgers University Press, 2005).

12 Oliver Bowles and K.G. Warner, 'Asbestos', Minerals Yearbook, ed. Herbert Hughes (Washington, DC: United States Government Printing Office, 1939), 1309.

13 For more on the different types of exposure in different work environments, see Tweedale, Magic Mineral.

14 'Asbestos Chronology', Asbestos Claims Research Facility, 4. This source was produced by Johns Manville solicitors in the 1980s and 1990s and comprises key primary documents from the company detailing corporate suppression of medical evidence.

15 'Asbestos Chronology', 4.

16 The type of asbestos found in Canada is chrysotile asbestos, whereas the type found in Zimbabwe is largely crocidolite. While there are some chemical differences between the two, 
both are hazardous to human health and cause asbestosis, lung cancer and mesothelioma, among other diseases.

17 Peter Bartrip, The Way from Dusty Death: Turner and Newall and the Regulation of Occupational Health in the British Asbestos Industry, 1890s-1970 (London: Athlone, 2001), 76.

18 'Asbestos Chronology', 4.

19 W.E. Cooke, 'Fibrosis of the Lungs due to the Inhalation of Asbestos Dust', British Medical Journal 2 (1924): 140-2, 147.

20 William N. Rom and Steven B. Markowitz (eds), Environmental and Occupational Medicine (Lippincott: Williams \& Wilkins, 2007), 493.

21 Jessica van Horssen, "À faire un peu de poussière": Environmental Health and the Asbestos Strike of 1949', Labour/LeTravail 70 (Fall 2012): 101-32.

22 The diagnosis of asbestosis in Canadian asbestos workers is one of controversy, as the companies that operated the mines had their own doctors tending to their employees, and they rarely informed them of their disease, instead attributing poor breathing to the fact that many of them smoked cigarettes.

23 See, for example, Yorkshire Post and Leeds Intelligencer (22 July 1927): 10, and Essex Newsman (7 December 1929): 3.

24 Jock McCulloch and Geoffrey Tweedale, Defending the Indefensible: The Global Asbestos Industry and Its Fight for Survival (Oxford: Oxford University Press, 2008).

25 Gérard Filion, Le Devoir (15 January 1949).

26 Van Horssen, A Town Called Asbestos.

27 Display ad 16, Manchester Guardian (26 November 1919): 9.

28 Display ad 46, Manchester Guardian (25 November 1920): 3.

29 'Lord Mayor's Appeal: Two Million Shillings', Manchester Guardian (20 October 1923): 14.

30 'For Diagnosis and Treatment', Manchester Guardian (5 February 1935): 12.

31 Graham Phythian, Blitz Britain: Manchester and Salford (Stroud: The History Press, 2015).

32 See, for example, Guy Hodgson, War Torn: Manchester, Its Newspapers and the Luftwaffe's Christmas Blitz of 1940 (Chester: University of Chester Press, 2015).

33 Sonia Zhuravlyova, 'War, Prefabs and an Unlikely Friendship Between Opposing Soldiers', Guardian (5 June 2014).

34 See Barbara Vale, Prefabs: The History of the UK Temporary Housing Programme (London: Routledge, 2003).

35 Van Horssen, A Town Called Asbestos, 50.

36 Leroy Gardner, Saranac Laboratory, to Hektoen, JM, 15 March 1943. 'Doc. 7', 31, and Dr Leroy Gardner, 'Draft Report', 'Doc. 7', Asbestos Claims Research Facility, 29.

37 Gerrit W.H. Schepers, 'Chronology of Asbestos Cancer Discoveries: Experimental Studies of the Saranac Laboratory', American Journal of Industrial Medicine 27 (1995): 602-3.

38 E.E. Keal, 'Asbestosis and Abdominal Neoplasms', Lancet (December 1960): 1211.

39 Quebec Asbestos Mining Association Meeting Minutes, 10 August 1967, 38 and March 1968, 3, Asbestos Claims Research Facility.

40 Standish Meacham, Regaining Paradise: Englishness and the Early Garden City Movement (New Haven: Yale University Press, 1999), 181.

41 Nancy Jacobs, Environment, Power, and Injustice: A South African History (Cambridge: Cambridge University Press, 2003), 221.

42 Jacobs, Environment, Power, and Injustice, 221.

43 Wythenshawe Community Housing Group, 'Asbestos in the Home: Guidance for Tenants'. Wythenshawe Community Housing Group, no date. 